\title{
Diagnóstico de impacto ambiental referente ao depósito de resíduos sólidos urbanos (RSUS) no contato entre o bairro Cidade de Deus e o Loteamento Alameda das Flores, em Viçosa/AL
}

\author{
Diagnosis of environmental impact related to the deposit of solid \\ urban waste (RSUS) in the contact between the Cidade de Deus \\ neighborhood and the Alameda das Flores Subdivision, in Viçosa/AL
}

\author{
Everson de Oliveira Santos ${ }^{1}$; Cirlene Jeane Santos e Santos ${ }^{2}$; \\ Paulo Ricardo Petter Medeiros ${ }^{3}$; Letícia Rosendo Correia Souza ${ }^{4}$; \\ Jarbas Macena de Oliveira Júnior ${ }^{5}$; João Victor Alves de Lima ${ }^{6}$; \\ Ingrid Thainã Vieira da Silva ${ }^{7}$
}

\footnotetext{
(1)Mestrando do curso de Pós-Graduação em Geografia da Universidade Federal de Alagoas (UFAL) - Área de concentração: Organização do Espaço Geográfico; Linha de pesquisa: Dinâmica Socioambiental e Geoprocessamento. Pós-graduado (Especialização) em Geografia e Meio Ambiente pela Universidade Cândido Mendes (UCAM-RJ). Bacharel e Licenciado em Geografia pela UFAL. Email: eversonoliveira2007.2@gmail.com.

(2) Docente da UFAL e coordenadora do Núcleo de Estudos Agrários e Dinâmicas Territoriais (NUAGRÁRIO). Bacharel e Licenciada e Mestra pela Universidade Federal da Bahia (UFBA) e Doutora em Geografia (Geografia Humana) pela Universidade de São Paulo (USP).E-mail: cirlene@igdema.ufal.br.

${ }^{(3)}$ Docente da Universidade Federal de Alagoas. Doutor em Geociências (Geoquímica) pela Universidade Federal Fluminense (UFF). E-mail: paulopetteraulas@hotmail.com.

(4)Mestra em Sociologia e graduada em Ciências Sociais pela UFAL. Atualmente é docente de Sociologia da Escola Estadual Joaquim Diegues e integrante do Grupo de Pesquisa Periferia, Afetos e Economia das Simbolizações (GRUPPAES). E-mail: leh.ufal@hotmail.com.

${ }^{(5)}$ Graduado em Ciências Biológicas pelo Instituto de Ciências Biológicas e da Saúde (ICBS) da UFAL. Pós-graduado (especialista) em Análises Clínicas pela Faculdade Internacional de Curitiba-PR (FACINTER).E-mail: montekio18@yahoo.com.br.

${ }^{(6)}$ Graduando em Geografia Licenciatura pela UFAL. E-mail: joaovictoralvesdelima12@gmail.com.

(7)Bacharel em Direito pelo Centro Universitário CESMAC. Advogada (OAB - 17168/AL). E-mail: ingrid.t.silva@outlook.com.

Todo o conteúdo expresso neste artigo é de inteira responsabilidade dos seus autores.
}

Recebido em: O1de outubro de 2019; Aceito em: 05 de janeiro de 2020; publicado em 10 de 01 de 2020. Copyright (C) Autor, 2020.

RESUMO: O presente trabalho destaca a formação de um depósito de resíduo sólido, conhecido popularmente como lixão, no contato entre o bairro Cidade de Deus e o Loteamento Alameda das Flores, no município de Viçosa - AL. A abordagem parte do pressuposto da necessidade de implantação do Saneamento Básico em sua plenitude para as populações das cidades. O que nem sempre é realizado pelas Prefeituras e/ou Governos Estaduais, ficando as populações desassistidas em sua maioria, considerando que acesso a água tratada, esgotamento sanitário e coleta regular de lixo, muitas vezes se constituem um privilégio destinado a poucos. Balizado em levantamento bibliográfico documental e em pesquisa exploratória de campo, foi possível traçar um breve diagnóstico da situação dos bairros, fundamentado nas leis que regem a temática, propondo por fim um conjunto de medidas mitigadoras visando equacionar o desconforto vivenciado pelos moradores do bairro Cidade de Deus e o Loteamento Alameda das Flores.

PALAVRAS-CHAVE: Saneamento básico,Descarte de lixo, Diagnóstico ambiental.

ABSTRACT: The present work highlights the formation of a solid waste deposit, popularly known as dump, in the contact between the Cidade de Deus neighborhood and the Alameda das Flores subdivision, in the municipality of Viçosa - AL. The approach is based on the assumption of the need to implement Basic Sanitation in its entirety for the populations of cities. This is not always done by City Halls and / or State Governments, with the majority of the populations being unassisted, considering that access to treated water, sanitation and regular garbage collection are often a privilege intended for a few. Based on a documentary bibliographic survey and exploratory field research, it was possible to draw a brief diagnosis of the situation of the neighborhoods, based on the laws that govern the theme, finally proposing a set of mitigating measures aiming to resolve the discomfort experienced by the residents of the Cidade de Deus and the Alameda das Flores subdivision.

KEYWORDS: Basic sanitation, Waste disposal, Environmental diagnosis. 
DIAGNÓSTICO DE IMPACTO AMBIENTAL REFERENTE AO DEPÓSITO DE RESÍDUOS SÓLIDOS URBANOS (RSUS) NO CONTATO ENTRE O BAIRRO CIDADE DE DEUS E O LOTEAMENTO ALAMEDA DAS FLORES, EM

DIAGNOSIS OF ENVIRONMENTAL IMPACT RELATED TO THE DEPOSIT OF SOLID URBAN WASTE (RSUS) IN THE CONTACT BETWEEN THE CIDADE DE DEUS NEIGHBORHOOD AND THE ALAMEDA DAS FLORES LUBDIVISION, IN VIÇOSA/AL

SANTOS, Everson de Oliveira; SANTOS, Cirlene Jeane Santos e; MEDEIROS, Paulo Ricardo Petter; SOUZA, Letícia Rosendo Correia; OLIVEIRA JÚNIOR, Jarbas Macena de; LIMA, João Victor Alves de; SILVA, Ingrid Thainã Vieira da

\section{INTRODUÇÃO}

O presente documento intitulado "Diagnóstico de impacto ambiental referente ao depósito de Resíduos Sólidos Urbanos (RSUS) no contato entre o Bairro Cidade de Deus e o Loteamento Alameda das Flores, em Viçosa - AL”, traz um Diagnóstico acerca dos problemas pontuais relacionados ao depósito de resíduos sólidos na entrada da instalação do Loteamento.

Entre os muitos assuntos abordados neste estudo de caso, tem-se a questão do crescimento das cidades sem um planejamento adequado e as consequências de tal fenômeno. Discute a complexidade conceitual do Saneamento Básico como instrumento de qualidade de vida e as implicações de sua não efetivação adequada. Fala também sobre como a legislação aborda a questão do lixo urbano e como os órgãos competentes devem garantir uma cidade mais justa, cidadã e igualitária.

Esse documento apresenta de maneira detalhada as implicações socioambientais e econômicas do lixão e propõe medidas de controle e mitigação, sendo as mesmas dentro das possibilidades legais e garantias de competências departamentais.

Portanto, o referido trabalho visa contribuir com um arcabouço teórico, técnico e jurídico para que seja encontrado um caminho viável de garantir a melhoria, por exemplo, do meio ambiente e da saúde da população residente tanto no Loteamento Alameda das Flores, como no Mutirão Cidade de Deus.

\section{O CRESCIMENTO DAS CIDADES E O SANEAMENTO BÁSICO}

O crescimento das cidades vem ocorrendo sem a utilização de uma importante estratégia que busca garantir um espaço urbano mais justo e igualitário: o planejamento urbano. Sem planejamento o processo de uso e ocupação do solo urbano tem acontecido afastado do devido controle por parte do Estado. Um dos pontos críticos dessa questão é o saneamento básico, este está estruturado em quatro pilares importantes, a saber: esgotamento sanitário, manejo dos resíduos sólidos, abastecimento de água e drenagem de águas pluviais, ver figura 1. 
DIAGNÓSTICO DE IMPACTO AMBIENTAL REFERENTE AO DEPÓSITO DE RESÍDUOS SÓLIDOS URBANOS (RSUS) NO CONTATO ENTRE O BAIRRO CIDADE DE DEUS E O LOTEAMENTO ALAMEDA DAS FLORES, EM

VIÇOSA/AL

DIAGNOSIS OF ENVIRONMENTAL IMPACT RELATED TO THE DEPOSIT OF SOLID URBAN WASTE (RSUS) IN THE CONTACT BETWEEN THE CIDADE DE DEUS NEIGHBORHOOD AND THE ALAMEDA DAS FLORES LUBDIVISION, IN VIÇOSA/AL

SANTOS, Everson de Oliveira; SANTOS, Cirlene Jeane Santos e; MEDEIROS, Paulo Ricardo Petter; SOUZA, Letícia Rosendo Correia; OLIVEIRA JÚNIOR, Jarbas Macena de; LIMA, João Victor Alves de; SILVA, Ingrid Thainã Vieira da

Figura 1. Esquema explicativo do conceito de Saneamento Básico.

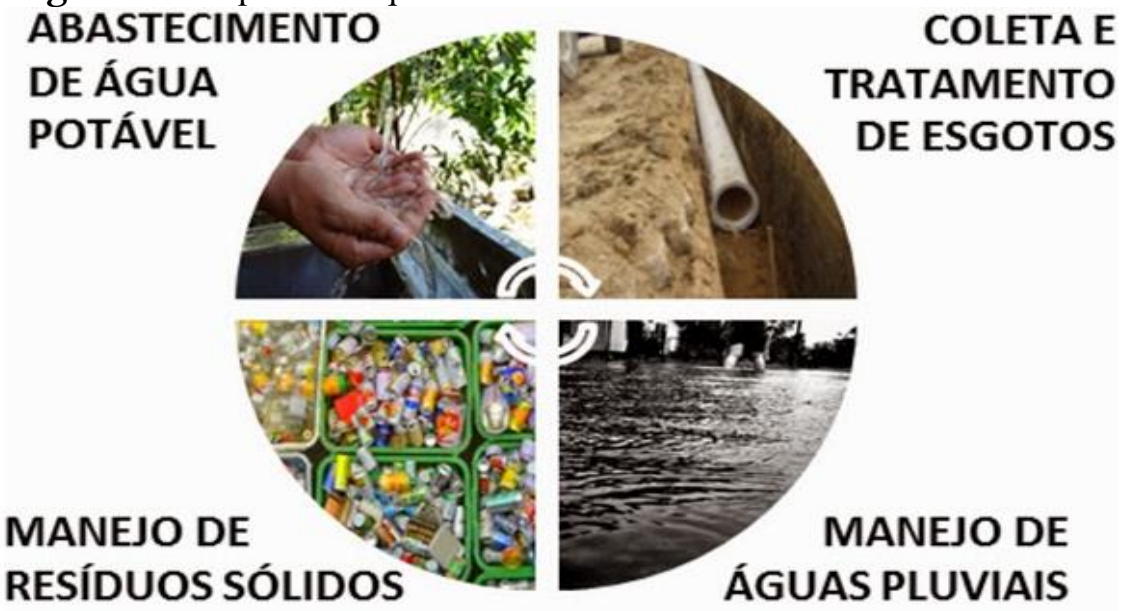

Fonte: EcoValor Consultoria e Ssutentabilidade. Disponível em:

https://www.ecovalor.eco.br/site/o-futuro-do-saneamento-na-valorizacao-do-esgoto/

É especificamente sobre o manejo dos resíduos sólidos e a limpeza urbana de que se ocupa o presente Diagnóstico de Impacto Ambiental. A ineficiência da mesma ou falta de coleta em locais pontuais do espaço urbano pode acarretar uma série de problemas para o meio ambiente, e mais, tal limpeza pública é um direito do cidadão e o poder público tem obrigação legal de garantir isso.

A Lei n. 11.445/2007 que estabelece diretrizes nacionais para o saneamento básico, esclarece em seu Art. $3^{\circ}$, I, alínea c, que a "limpeza urbana e manejo de resíduos sólidos: conjunto de atividades, infraestruturas e instalações operacionais de coleta, transporte, transbordo, tratamento e destino final do lixo doméstico e do lixo originário da varrição e limpeza de logradouros e vias públicas".

É fundamental que o poder público se empenhe em atuar na melhoria e estruturação de um saneamento básico que garanta qualidade de vida e saúde das populações das cidades. Estas premissas são prejudicadas quando se tem, por exemplo, problemas de coleta de lixo urbano e, por conseguinte, o meio ambiente passa a ser degradado também.

\section{Loteamento Alameda das Flores: características e localização geográfica}

O empreendimento "Loteamento Alameda das Flores" parte da iniciativa do empresário Antônio Tenório Filho, no ano de 2012. O processo de loteamento, uso e 
DIAGNÓSTICO DE IMPACTO AMBIENTAL REFERENTE AO DEPÓSITO DE RESÍDUOS SÓLIDOS URBANOS (RSUS) NO CONTATO ENTRE O BAIRRO CIDADE DE DEUS E O LOTEAMENTO ALAMEDA DAS FLORES, EM

VIÇOSA/AL

DIAGNOSIS OF ENVIRONMENTAL IMPACT RELATED TO THE DEPOSIT OF SOLID URBAN WASTE (RSUS) IN THE CONTACT BETWEEN THE CIDADE DE DEUS NEIGHBORHOOD AND THE ALAMEDA DAS FLORES LUBDIVISION, IN VIÇOSA/AL

SANTOS, Everson de Oliveira; SANTOS, Cirlene Jeane Santos e; MEDEIROS, Paulo Ricardo Petter; SOUZA, Letícia Rosendo Correia; OLIVEIRA JÚNIOR, Jarbas Macena de; LIMA, João Victor Alves de; SILVA, Ingrid Thainã Vieira da

ocupação do solo urbano e a consequente construção de habitações ocorre, segundo documento de Registro de Imóveis do Cartório de Serviços Notoriais e Registrais de Viçosa - Alagoas, em um terreno situado na rua L, área 03, do Conjunto Residencial Cidade de Deus. Possui uma área total de 15.789,00 m², iniciando-se na frente com a distância de 37,50 metros, confrontando-se com a rua L, do Mutirão Cidade de Deus, área 03, chega-se ao lado, direito. No lado direito confronta-se com outro térreo do Sr. Antônio Tenório Filho, terreno do Sr. Sebastião Pereira de Figueiredo e terreno do Se. Juvenal com uma distância de 288,45 metros, chega-se ao lado esquerdo. No lado esquerdo com uma distância de 302,20 metros, confronta-se com fundos de quintais de residências do Mutirão Cidade de Deus área 04, rua C.

O Loteamento possui como coordenada geográfica: $9^{\circ} 22^{\prime} 58.6^{\prime}$ Latitude Sul e $36^{\circ}$ 14'22.7" Longitude Oeste. O mesmo está localizado no município de Viçosa, Estado de Alagoas. O município de Viçosa faz parte da Mesorregião do Leste Alagoano e Microrregião Serrana dos Quilombos.

Abaixo tem-se um recorte que destaca a extensão do Loteamento Alameda das Flores no espaço urbano, bem como destaca a área do empreendimento.

Figura 2. Mapa destacando a amplitude de área do Loteamento Alameda das Flores.

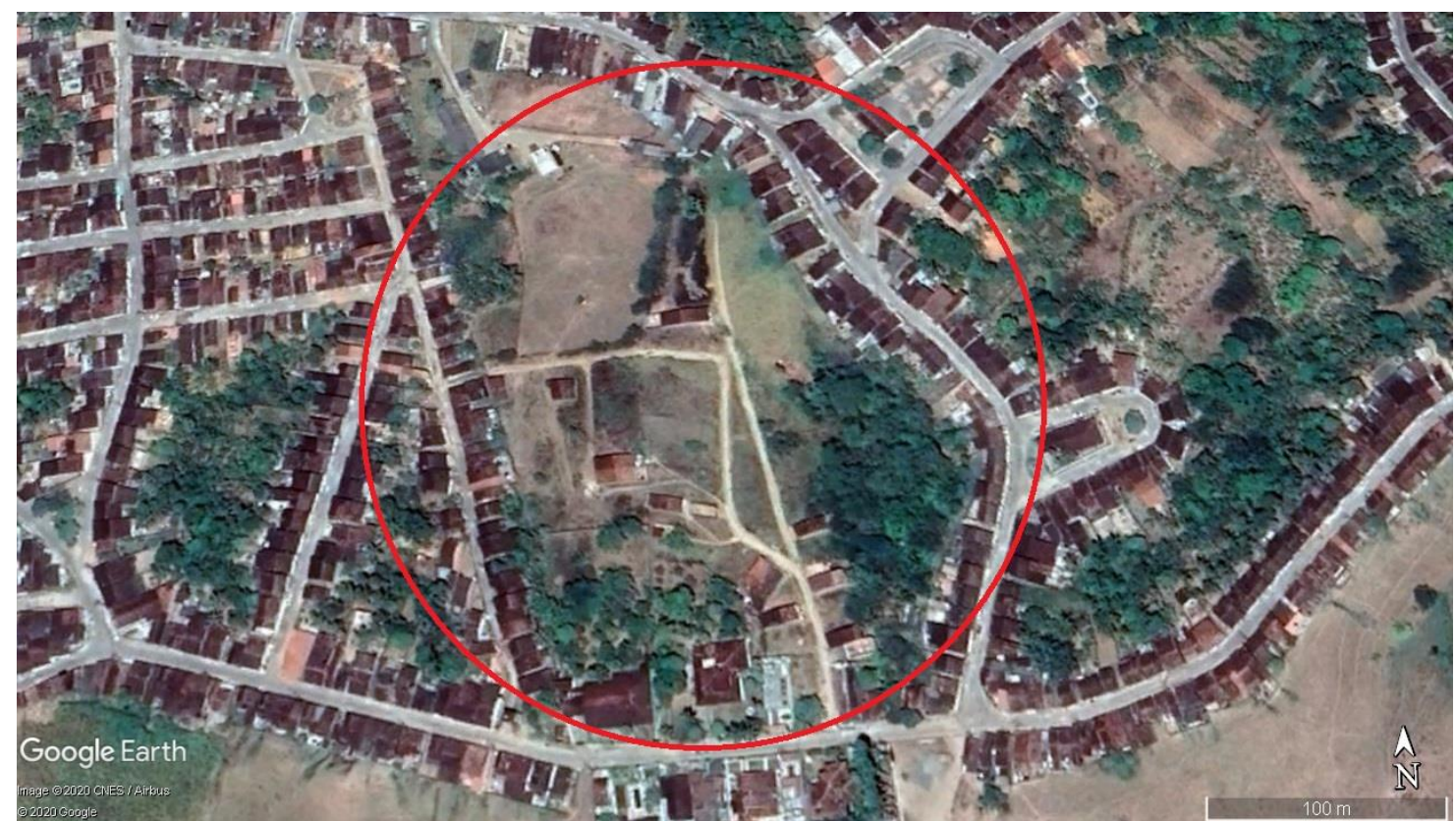

Fonte: Google Earth, 2020. 
DIAGNÓSTICO DE IMPACTO AMBIENTAL REFERENTE AO DEPÓSITO DE RESÍDUOS SÓLIDOS URBANOS (RSUS) NO CONTATO ENTRE O BAIRRO CIDADE DE DEUS E O LOTEAMENTO ALAMEDA DAS FLORES, EM

DIAGNOSIS OF ENVIRONMENTAL IMPACT RELATED TO THE DEPOSIT OF SOLID URBAN WASTE (RSUS) IN THE CONTACT BETWEEN THE CIDADE DE DEUS NEIGHBORHOOD AND THE ALAMEDA DAS FLORES LUBDIVISION, IN VIÇOSA/AL

SANTOS, Everson de Oliveira; SANTOS, Cirlene Jeane Santos e; MEDEIROS, Paulo Ricardo Petter; SOUZA, Letícia Rosendo Correia; OLIVEIRA JÚNIOR, Jarbas Macena de; LIMA, João Victor Alves de; SILVA, Ingrid Thainã Vieira da

\section{A coleta seletiva de lixo urbano}

A operação de coleta engloba, desde a partida do veículo de sua garagem, compreendendo todo o percurso gasto na viagem para remoção dos resíduos dos locais onde foram acondicionados aos locais de descarga, até o retorno ao ponto de partida. A eficiência da coleta seletiva garante saúde e bem-estar da população. (PENNA, 2015, p. 17)

Segundo Penna (2015, p. 17), a coleta normalmente pode ser classificada em dois tipos de sistemas: sistema especial de coleta (resíduos contaminados) e sistema de coleta de resíduos não contaminados. Nesse último, a coleta pode ser realizada de maneira convencional (resíduos são encaminhados para o destino final) ou seletiva (resíduos recicláveis que são encaminhados para locais de tratamento e/ou recuperação).

Em se tratando dos tipos de veículos coletores, os mesmos são os mais diversos. Uma primeira grande classificação seria dividi-los em motorizados e não-motorizados (os que utilizam a tração animal como força motriz). Os motorizados podem ser divididos em compactadores, que, segundo Roth et al citado por Cunha e Caixeta Filho (2002), podem reduzir a 1/3 o volume inicial dos resíduos, e comuns (tratores, coletor de caçamba aberta e coletor com carrocerias tipo prefeitura ou baú). Há também os caminhões multi-caçamba utilizados na coleta seletiva de recicláveis, em que os materiais coletados são alocados, separadamente dentro da carroceria do caminhão.

É importante ressaltar que segundo Dias (2008), outro fato agravante é a disposição final dos resíduos produzidos nos centros urbanos, de forma desordenada e sem um planejamento técnico, pois áreas são ocupadas com a deposição de lixo sem tratamento, áreas estas que, a curto e médio prazo, inviabilizam a sua utilização para outros fins, agredindo de forma drástica o meio ambiente e tornando vulneráveis à contaminação, os mananciais de água, sem contar que geralmente são áreas o mais próximo possível dos centros produtores de lixo, no sentido de diminuir os custos operacionais de transporte.

Segundo UFV/Lesa (2008), para ajudar a diminuir o lixo temos a fórmula dos RE's que consiste numa apresentação sugestiva de como se pode atingir o objetivo de conscientização para a prática de reaproveitamento de materiais em busca da qualidade de vida e preservação do meio ambiente: 
DIAGNÓSTICO DE IMPACTO AMBIENTAL REFERENTE AO DEPÓSITO DE RESÍDUOS SÓLIDOS URBANOS

DIAGNOSIS OF ENVIRONMENTAL IMPACT RELATED TO THE DEPOSIT OF SOLID URBAN WASTE (RSUS) IN THE CONTACT BETWEEN THE CIDADE DE DEUS NEIGHBORHOOD AND THE ALAMEDA DAS FLORES LUBDIVISION, IN VIÇOSA/AL

SANTOS, Everson de Oliveira; SANTOS, Cirlene Jeane Santos e; MEDEIROS, Paulo Ricardo Petter; SOUZA, Letícia Rosendo Correia; OLIVEIRA JÚNIOR, Jarbas Macena de; LIMA, João Victor Alves de; SILVA, Ingrid Thainã Vieira da

- RE duzira geração de lixo;

- RE utilizar os bens de consumo;

- RE cuperar os materiais;

- RE ciclar;

- RE pensar os hábitos de consumo e de descarte.

Monteiro et al (2001), define tratamento como uma série de procedimentos destinados a reduzir a quantidade ou o potencial poluidor dos resíduos sólidos, seja impedindo descarte de lixo em ambiente ou local inadequado, seja transformando-o em material inerte ou biologicamente estável. O tratamento mais eficaz é o prestado pela própria população, quando está empenhada em reduzir a quantidade de lixo, evitando o desperdício, reaproveitando os materiais, separando os recicláveis em casa ou na própria fonte e se desfazendo do lixo que produz de maneira correta, que acaba por fazer parte da coleta seletiva.

Além desses procedimentos, o mesmo autor diz que existem processos físicos e biológicos que objetivam estimular a atividade dos microrganismos que atacam o lixo, decompondo a matéria orgânica e causando poluição.

\section{RESÍDUOS SÓLIDOS URBANOS}

Em se tratando de definição, o lixo pode ser definido como o conjunto de restos de atividades humanas. Estes podem ser classificados por quem os produz como inúteis, indesejáveis ou descartáveis. Outro aspecto importante é que o lixo produzido pela sociedade pode se apresentar no estado líquido, sólido ou semi-sólido.

A NBR 10.004/ 87 classifica, de acordo com sua periculosidade, os resíduos sólidos podem ser enquadrados como:

Classe I - resíduos perigosos

São aqueles que apresentam periculosidade ou uma das características seguintes: inflamabilidade, corrosividade, reatividade, toxicidade ou patogenicidade.

Classe II - Não-inertes 
DIAGNÓSTICO DE IMPACTO AMBIENTAL REFERENTE AO DEPÓSITO DE RESÍDUOS SÓLIDOS URBANOS

DIAGNOSIS OF ENVIRONMENTAL IMPACT RELATED TO THE DEPOSIT OF SOLID URBAN WASTE (RSUS) IN THE CONTACT BETWEEN THE CIDADE DE DEUS NEIGHBORHOOD AND THE ALAMEDA DAS FLORES LUBDIVISION, IN VIÇOSA/AL

SANTOS, Everson de Oliveira; SANTOS, Cirlene Jeane Santos e; MEDEIROS, Paulo Ricardo Petter; SOUZA, Letícia Rosendo Correia; OLIVEIRA JÚNIOR, Jarbas Macena de; LIMA, João Victor Alves de; SILVA, Ingrid Thainã Vieira da

São aqueles que não se enquadram na classe I ou III. Os resíduos classe II podem ter as seguintes propriedades: combustibilidade, biodegradabilidade ou solubilidade em água.

Classe III - inertes

Segundo Zanta e Ferreira (2006), são aqueles que, por suas características intrínsecas, não oferecem riscos à saúde e ao meio ambiente. Além disso, quando amostrados de forma representativa, segundo a norma NBR 10.007, e submetidos a um contato estático ou dinâmico com água destilada ou deionizada, a temperatura ambiente, conforme teste de solubilização segundo a norma NBR 10.006, não têm nenhum de seus constituintes solubilizados a concentrações superiores aos padrõesde potabilidade da água, conforme listagem $n^{\circ} 8$, constante do Anexo H da NBR 10.004, excetuando-se os padrões de aspecto, cor, turbidez e sabor.

De acordo com Monteiro et al (2001), a origem é o principal elemento para a caracterização dos resíduos sólidos. Segundo este critério, os diferentes tipos de lixo podem ser agrupados em cinco classes, a saber:

- Lixo doméstico ou residencial;

- Lixo comercial;

- Lixo público;

- Lixo domiciliar especial: entulho de obras, pilhas e baterias, lâmpadas fluorescentes, pneus;

- Lixo de fontes especiais: industrial, radioativo, de portos, aeroportos e terminais rodoferroviários, agrícola e resíduos dos serviços de saúde.

Quanto aos componentes do lixo, eles podem ser diferenciados nas seguintes categorias: matéria orgânica putrescível; plástico; papel/papelão; vidro; metal ferroso; metal não ferroso; pano, trapo, couro e borracha; madeira; contaminante biológico e contaminante químico; pedra, terra e cerâmica; e diversos. Deve-se sempre explicitar o teor de umidade presente, uma vez que o peso dos resíduos orgânicos é determinado em condição úmida. Na tabela 01, apresentam-se exemplos de materiais que podem compor cada categoria, observando-se a grande diversidade de materiais (PENNA, 2015, p. 12). 
DIAGNOSIS OF ENVIRONMENTAL IMPACT RELATED TO THE DEPOSIT OF SOLID URBAN WASTE (RSUS) IN THE CONTACT BETWEEN THE CIDADE DE DEUS NEIGHBORHOOD AND THE ALAMEDA DAS FLORES LUBDIVISION, IN VIÇOSA/AL

SANTOS, Everson de Oliveira; SANTOS, Cirlene Jeane Santos e; MEDEIROS, Paulo Ricardo Petter; SOUZA, Letícia Rosendo Correia; OLIVEIRA JÚNIOR, Jarbas Macena de; LIMA, João Victor Alves de; SILVA, Ingrid Thainã Vieira da

Tabela 1. Categorias de tipologias de lixo e exemplos.

\begin{tabular}{|c|c|}
\hline CATEGORIAS & EXEMPLOS \\
\hline $\begin{array}{l}\text { MATÉRIA ORGÂNICA } \\
\text { PUTRESCÍVEL }\end{array}$ & Restos alimentares, flores, podas de árvores. \\
\hline PLÁSTICO & $\begin{array}{l}\text { Sacos, sacolas, embalagens de refrigerantes, água e leite, recipientes de } \\
\text { produtos de limpeis, esponjas, isopor, utensílios de cozinha, látex, sacos de } \\
\text { ráfia. }\end{array}$ \\
\hline PAPEL E PAPELÃO & Caixas, revistas, jornais, cartões, papel, pratos, cadernos, livros, pastas. \\
\hline VIDRO & $\begin{array}{l}\text { Copos, garrafas de bebidas, pratos, espelho, embalagens de produtos de } \\
\text { limpeza, embalagens de produtos de beleza, embalagens de produtos } \\
\text { alimentícios. }\end{array}$ \\
\hline METAL FERROSO & Palha de aço, alfinetes, agulhas, embalagens de produtos alimentícios. \\
\hline $\begin{array}{l}\text { METAL NÃO- } \\
\text { FERROSO }\end{array}$ & Latas de bebidas, restos de cobre, restos de chumbo, fiação elétrica. \\
\hline MADEIRA & Caixas, tábuas, palitos de fósforos, palitos de picolé, tampas, móveis, lenha. \\
\hline $\begin{array}{l}\text { PANOS, TRAPOS, } \\
\text { COURO E BORRACHA }\end{array}$ & $\begin{array}{l}\text { Roupas, panos de limpeza, pedaços de tecido, bolsas, mochilas, sapatos, } \\
\text { tapetes, luvas, cintos, balões. }\end{array}$ \\
\hline $\begin{array}{l}\text { CONTAMINANTE } \\
\text { QUÍMICO }\end{array}$ & $\begin{array}{l}\text { Pilhas, medicamentos, lâmpadas, inseticidas, raticidas, colas em geral, } \\
\text { cosméticos, vidro de esmaltes, embalagens de produtos químicos, latas de } \\
\text { óleo de motor, latas com tintas, embalagens pressurizadas, canetas com } \\
\text { carga, papel-carbono, filme fotográfico. }\end{array}$ \\
\hline $\begin{array}{l}\text { CONTAMINANTE } \\
\text { BIOLÓGICO }\end{array}$ & $\begin{array}{l}\text { Papel higiênico, cotonetes, algodão, curativos, gazes e panos com sangue, } \\
\text { fraldas descartáveis, absorventes higiênicos, seringas, laminas de barbear, } \\
\text { cabelos, pelos, embalagens de anestésicos, luvas. }\end{array}$ \\
\hline $\begin{array}{l}\text { PEDRA, TERRA E } \\
\text { CERÂMICA }\end{array}$ & $\begin{array}{l}\text { Vasos de flores, pratos, restos de construção, terra, tijolos, cascalho, pedras } \\
\text { decorativas }\end{array}$ \\
\hline DIVERSOS & $\begin{array}{l}\text { Velas de cera, restos de sabão e sabonete, carvão, giz, pontas de cigarro, } \\
\text { rolhas, cartões de crédito, lápis de cera, embalagens longa-vida, } \\
\text { embalagens metalizadas, sacos de aspirador de pó, lixas e outros materiais } \\
\text { de difícil identificação. }\end{array}$ \\
\hline
\end{tabular}

Fonte: Zanta e Ferreira (2006). Adaptação: Pessin et al. (2002).

Em relação ao acondicionamento do lixo, Cunha e Caixeta Filho (2002), a primeira etapa do processo de remoção dos resíduos sólidos corresponde à atividade de acondicionamento do lixo. Podem ser utilizados diversos tipos de vasilhames, como: vasilhas domiciliares, tambores, sacos plásticos, sacos de papel, contêineres comuns, contêineres basculantes, entre outros. No Brasil, percebe-se grande utilização de sacos plásticos. O lixo mal acondicionado significa poluição ambiental e risco à segurança da população, pois pode levar ao aparecimento de doenças. O lixo bem acondicionado facilita o processo de coleta.

Ainda segundo os autores acima, acondicionar os resíduos sólidos domiciliares significa prepará-los para a coleta de forma sanitariamente adequada, como ainda compatível com o tipo e a quantidade de resíduos. A qualidade da operação de coleta e transporte de lixo depende da forma adequada do seu acondicionamento, armazenamento 
DIAGNÓSTICO DE IMPACTO AMBIENTAL REFERENTE AO DEPÓSITO DE RESÍDUOS SÓLIDOS URBANOS (RSUS) NO CONTATO ENTRE O BAIRRO CIDADE DE DEUS E O LOTEAMENTO ALAMEDA DAS FLORES, EM

DIAGNOSIS OF ENVIRONMENTAL IMPACT RELATED TO THE DEPOSIT OF SOLID URBAN WASTE (RSUS) IN THE CONTACT BETWEEN THE CIDADE DE DEUS NEIGHBORHOOD AND THE ALAMEDA DAS FLORES LUBDIVISION, IN VIÇOSA/AL

SANTOS, Everson de Oliveira; SANTOS, Cirlene Jeane Santos e; MEDEIROS, Paulo Ricardo Petter; SOUZA, Letícia Rosendo Correia; OLIVEIRA JÚNIOR, Jarbas Macena de; LIMA, João Victor Alves de; SILVA, Ingrid Thainã Vieira da

e da disposição dos recipientes no local, dia e horários estabelecidos pelo órgão de limpeza urbana para a coleta. A população tem, portanto, participação decisiva nesta operação.

A importância do acondicionamento adequado está em:

- Evitar acidentes;

- Evitar a proliferação de vetores;

- Minimizar o impacto visual e olfativo;

- Reduzir a heterogeneidade dos resíduos (no caso de haver coleta seletiva);

- Facilitar a realização da etapa da coleta.

De acordo com Monteiro et al (2001), infelizmente, o que se verifica em muitas cidades é o surgimento espontâneo de pontos de acumulação de lixo domiciliar a céu aberto, expostos indevidamente ou espalhados nos logradouros, prejudicando o ambiente e arriscando a saúde pública.

\section{O que a legislação fala sobre os resíduos sólidos urbanos?}

Inicialmente, cabe destacar que a Constituição Federal de 1988 tutela a proteção ao meio ambiente como uma obrigação conjunta, conforme dispõe em seu Art. 225: “todos têm direito ao meio ambiente ecologicamente equilibrado, bem de uso comum do povo e essencial à sadia qualidade de vida, impondo-se ao Poder Público e à coletividade o dever de defendê-lo e preservá-lo para as presentes e futuras gerações”.

Nesse contexto, é preciso falar sobre a Política Nacional de Resíduos Sólidos (PNRS). A mesma é uma lei (Lei n ${ }^{\circ}$ 12.305/10) que organiza e estrutura a forma com que todas as cidades lidam com o lixo. Os pontos da lei elencados neste diagnóstico serão colocados levando em consideração a situação do referido estudo de caso.

Em seu Art. $6^{\circ}$ que fala sobre os princípios da Política Nacional de Resíduos Sólidos, é frisado o seguinte:

III - a visão sistêmica, na gestão dos resíduos sólidos, que considere as variáveis ambiental, social, cultural, econômica, tecnológica e de saúde pública.

VI - a cooperação entre as diferentes esferas do poder público, o setor empresarial e demais segmentos da sociedade; 
DIAGNÓSTICO DE IMPACTO AMBIENTAL REFERENTE AO DEPÓSITO DE RESÍDUOS SÓLIDOS URBANOS (RSUS) NO CONTATO ENTRE O BAIRRO CIDADE DE DEUS E O LOTEAMENTO ALAMEDA DAS FLORES, EM

VIÇOSA/AL

DIAGNOSIS OF ENVIRONMENTAL IMPACT RELATED TO THE DEPOSIT OF SOLID URBAN WASTE (RSUS) IN THE CONTACT BETWEEN THE CIDADE DE DEUS NEIGHBORHOOD AND THE ALAMEDA DAS FLORES LUBDIVISION, IN VIÇOSA/AL

SANTOS, Everson de Oliveira; SANTOS, Cirlene Jeane Santos e; MEDEIROS, Paulo Ricardo Petter; SOUZA, Letícia Rosendo Correia; OLIVEIRA JÚNIOR, Jarbas Macena de; LIMA, João Victor Alves de; SILVA, Ingrid Thainã Vieira da

IX - o respeito às diversidades locais e regionais;

$\mathrm{X}$ - o direito da sociedade à informação e ao controle social;

XI - a razoabilidade e a proporcionalidade.

Em seu Art. $7^{\circ}$, onde é determinado acerca dos objetivos da Política Nacional de Resíduos Sólidos, é esclarecido que:

I - proteção da saúde pública e da qualidade ambiental;

V - redução do volume e da periculosidade dos resíduos perigosos;

VIII - articulação entre as diferentes esferas do poder público, e destas com o setor empresarial, com vistas à cooperação técnica e financeira para a gestão integrada de resíduos sólidos;

$\mathrm{X}$ - regularidade, continuidade, funcionalidade e universalização da prestação dos serviços públicos de limpeza urbana e de manejo de resíduos sólidos, com adoção de mecanismos gerenciais e econômicos que assegurem a recuperação dos custos dos serviços prestados, como forma de garantir sua sustentabilidade operacional e financeira, observada a Lei $\mathrm{n}^{\mathrm{o}} 11.445$, de 2007.

Em seu Art. $8^{\circ}$, onde fala sobre os instrumentos da Política Nacional de Resíduos Sólidos, entre outros:

III - a coleta seletiva, os sistemas de logística reversa e outras ferramentas relacionadas à implementação da responsabilidade compartilhada pelo ciclo de vida dos produtos;

V - o monitoramento e a fiscalização ambiental, sanitária e agropecuária;

VII - a pesquisa científica e tecnológica;

VIII - a educação ambiental.

O Plano Diretor (Lei 740/2006) de Viçosa - Alagoas é outro documento legal que institui sobre as demandas discutidas aqui. Em seu Art. 36, falando sobre o saneamento básico, visto que em toda conjuntura conceitual do entendimento de saneamento básico, a questão dos resíduos sólidos é um dos pilares, é destacado que "são elementos referenciais para o saneamentobásico de Viçosa, os sistemas de abastecimento d'água, de esgotamento sanitário, de drenagem das águas pluviais e de limpeza pública, de modo a melhorar as condições de vida da população no município e impedir a degradação dos seus recursos naturais".

Em seu Art. 38: 
DIAGNÓSTICO DE IMPACTO AMBIENTAL REFERENTE AO DEPÓSITO DE RESÍDUOS SÓLIDOS URBANOS (RSUS) NO CONTATO ENTRE O BAIRRO CIDADE DE DEUS E O LOTEAMENTO ALAMEDA DAS FLORES, EM

DIAGNOSIS OF ENVIRONMENTAL IMPACT RELATED TO THE DEPOSIT OF SOLID URBAN WASTE (RSUS) IN THE CONTACT BETWEEN THE CIDADE DE DEUS NEIGHBORHOOD AND THE ALAMEDA DAS FLORES LUBDIVISION, IN VIÇOSA/AL

SANTOS, Everson de Oliveira; SANTOS, Cirlene Jeane Santos e; MEDEIROS, Paulo Ricardo Petter; SOUZA, Letícia Rosendo Correia; OLIVEIRA JÚNIOR, Jarbas Macena de; LIMA, João Victor Alves de; SILVA, Ingrid Thainã Vieira da

V -adequação do saneamento ambiental;

VIII -a inclusão do componente de educação ambiental nas medidas e ações voltadas a proteção ambiental.

Em seu Art. 43:

XIV - a conscientização da população para necessidade de minimizar a produção dos resíduos sólidos, buscando a implantação de ações para coleta seletiva na Cidade de Viçosa e Distritos.

\section{DIAGNÓSTICO DE IMPACTO AMBIENTAL}

O Diagnóstico de Impacto Ambiental é um documento técnicos multidisciplinar com o objetivo de realizar uma avaliação ampla, concreta e completa dos problemas ambientais significativos e, sobretudo, indicar medidas mitigadoras para os impactos identificados.

O presente documento, especificamente neste tópico, indica e detalha os problemas gerados pela existência do lixão a céu aberto na entrada principal ao Loteamento Alameda das Flores. No início da implantação do Loteamento o local era utilizado para o acúmulo irregular de lixo, no entanto, paulatinamente foi se constituindo em um lixão. Este pode ser definido como um local onde ocorre de forma inadequada à disposição final de resíduos sólidos, caracterizado pelo descarte irregular do lixo sobre o solo, sem medidas de proteção ao meio ambiente ou saúde pública.

De acordo com moradores do Loteamento, bem como outros cidadãos que residem em um bairro adjacente ao Loteamento, a saber: Mutirão Cidade de Deus (Área 3 e 4), a problemática é a seguinte:

- O carro coletor de lixo passa normalmente as segundas, quartas e sextas, mas não entra no Loteamento. Isso obriga os moradores subirem o declive até a entrada do mesmo para colocar o lixo doméstico tanto na rua principal como no próprio "lixão"; 
DIAGNÓSTICO DE IMPACTO AMBIENTAL REFERENTE AO DEPÓSITO DE RESÍDUOS SÓLIDOS URBANOS (RSUS) NO CONTATO ENTRE O BAIRRO CIDADE DE DEUS E O LOTEAMENTO ALAMEDA DAS FLORES, EM

DIAGNOSIS OF ENVIRONMENTAL IMPACT RELATED TO THE DEPOSIT OF SOLID URBAN WASTE (RSUS) IN THE CONTACT BETWEEN THE CIDADE DE DEUS NEIGHBORHOOD AND THE ALAMEDA DAS FLORES LUBDIVISION, IN VIÇOSA/AL

SANTOS, Everson de Oliveira; SANTOS, Cirlene Jeane Santos e; MEDEIROS, Paulo Ricardo Petter; SOUZA, Letícia Rosendo Correia; OLIVEIRA JÚNIOR, Jarbas Macena de; LIMA, João Victor Alves de; SILVA, Ingrid Thainã Vieira da

- Quando o carro coletor passa, são recolhidos apenas algumas sacolas de lixo doméstico, em sua grande maioria, o lixo ali depositado fica empilhado por muitos dias;

- Moradores de áreas diferentes e que não pertencem às adjacências se deslocam até o lixão em estudo para depositar seu lixo doméstico;

- Animais ficam no lixão abrindo as sacolas de lixo e isso espalha tudo pela entrada do Loteamento e na rua principal;

- Após as chuvas muito lixo é carregado pela água.

\section{Impactos socioambientais identificados}

Mediante o estudo de campo, da equipe multiprofissional foi possível identificar os problemas ambientais existentes e após a sistematização das observações realizadas agrupar e caracterizar tecnicamente os mesmos, como pode ser verificado nos subtópicos que se seguem.

\section{Saúde humana e meio ambiente}

O descarte de lixos os mais variados representam um risco à saúde humana e de moradores não apenas do próprio Loteamento em questão, mas da população residente nas adjacências. Foi verificado que nos lixos descartados há medicamentos e isso representa riscos não apenas de saúde, mas, sobretudo, ao meio ambiente.

Após uma precipitação pluviométrica (chuvas), por ex emplo, ocorre o processo de lixiviação e isso ocasiona a lavagem do solo e muitos desses medicamentos descartados de maneira incorreta pela população, com tais sacolas de lixo doméstico, permanecerão por um longo período no local, os resíduos químicos dos medicamentos acabam contaminando o solo e se diluindo na água que infiltra e vai até o lençol freático. Acrescendo o fato de que a chuva consegue levar parte domaterial do lixo pela rua principal do Mutirão Cidade de Deus (área 4)

Além de remédios, luvas cirúrgicas fazem parte do conteúdo de lixo doméstico do lixão em questão. Não é o descarte apropriado e isso acaba por gerar problemas na 
DIAGNÓSTICO DE IMPACTO AMBIENTAL REFERENTE AO DEPÓSITO DE RESÍDUOS SÓLIDOS URBANOS (RSUS) NO CONTATO ENTRE O BAIRRO CIDADE DE DEUS E O LOTEAMENTO ALAMEDA DAS FLORES, EM

DIAGNOSIS OF ENVIRONMENTAL IMPACT RELATED TO THE DEPOSIT OF SOLID URBAN WASTE (RSUS) IN THE CONTACT BETWEEN THE CIDADE DE DEUS NEIGHBORHOOD AND THE ALAMEDA DAS FLORES LUBDIVISION, IN VIÇOSA/AL

SANTOS, Everson de Oliveira; SANTOS, Cirlene Jeane Santos e; MEDEIROS, Paulo Ricardo Petter; SOUZA, Letícia Rosendo Correia; OLIVEIRA JÚNIOR, Jarbas Macena de; LIMA, João Victor Alves de; SILVA, Ingrid Thainã Vieira da

chamada biossegurança. As luvas de procedimento que estiveram em contato com fluidos corporais, sangue ou outras substâncias podem causar a disseminação de microrganismos, doenças e substâncias tóxicas, ver figuras 4, 5 e 6.

Figura 4. Luva cirúrgica em lixo doméstico no lixão a céu aberto.

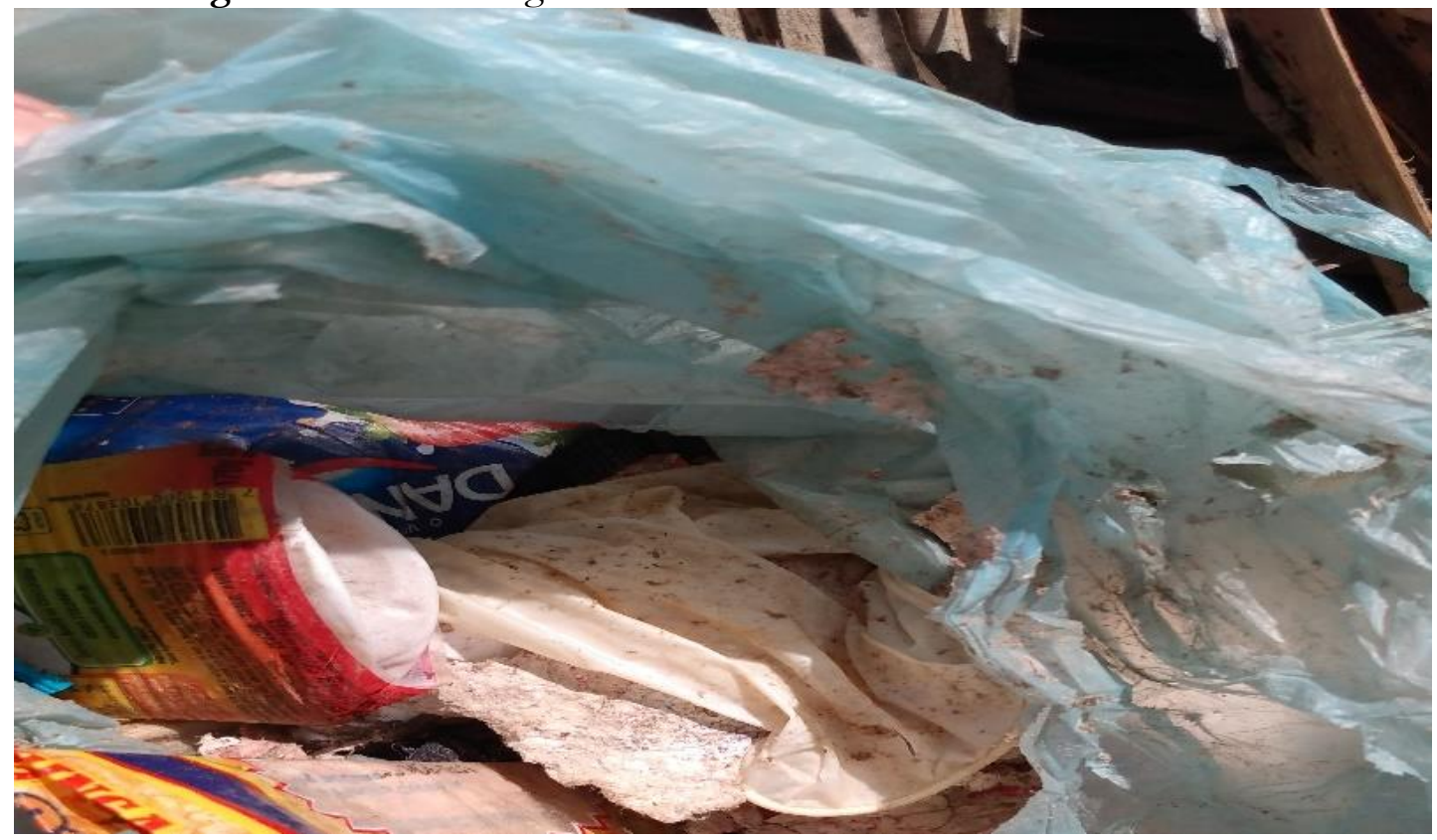

Fonte: Acervo dos autores, 2020.

Figura 5. Exemplo de medicamento descartado ainda contendo o restante de resíduo químico.

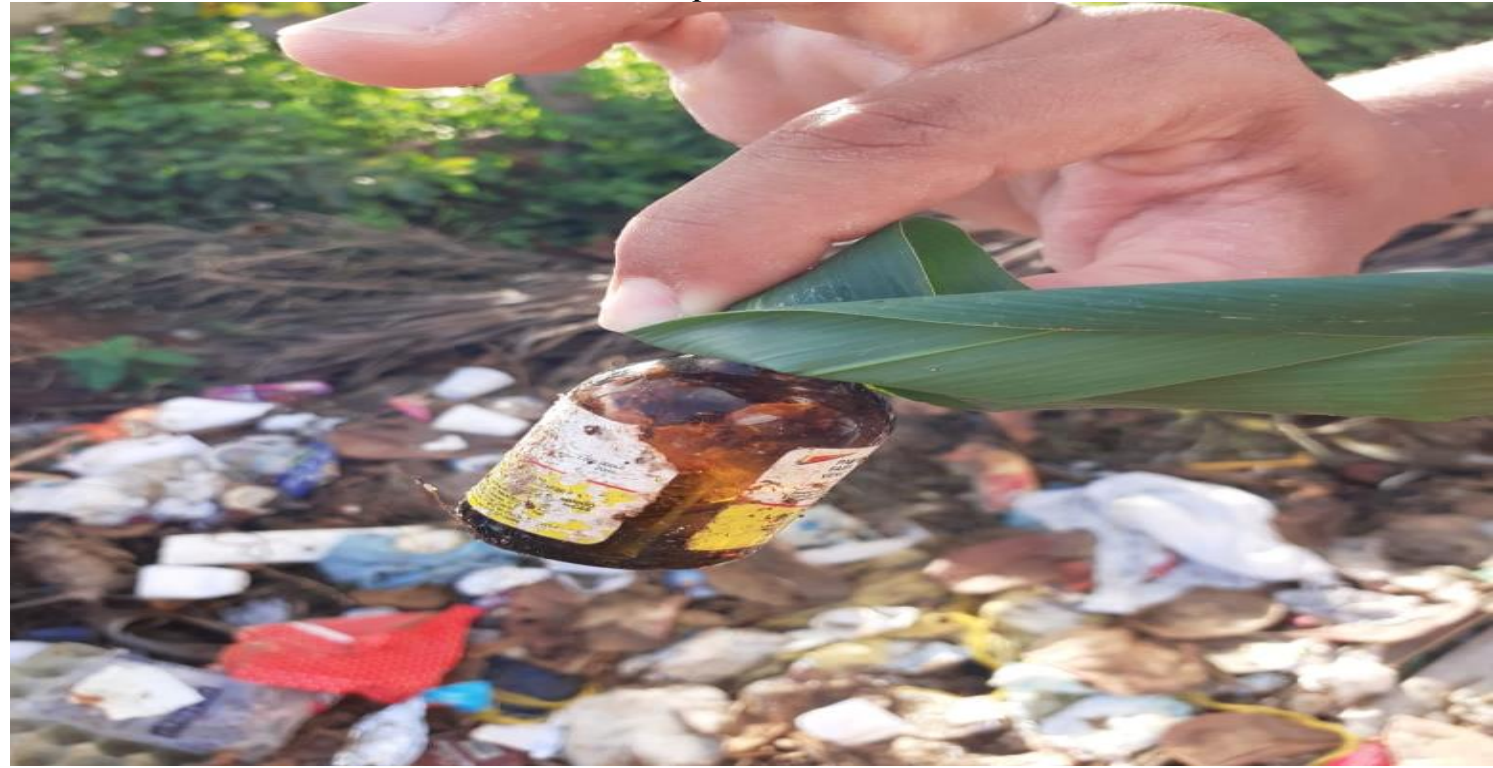

Fonte: Acervo dos autores, 2020. 
DIAGNÓSTICO DE IMPACTO AMBIENTAL REFERENTE AO DEPÓSITO DE RESÍDUOS SÓLIDOS URBANOS (RSUS) NO CONTATO ENTRE O BAIRRO CIDADE DE DEUS E O LOTEAMENTO ALAMEDA DAS FLORES, EM

DIAGNOSIS OF ENVIRONMENTAL IMPACT RELATED TO THE DEPOSIT OF SOLID URBAN WASTE (RSUS) IN THE CONTACT BETWEEN THE CIDADE DE DEUS NEIGHBORHOOD AND THE ALAMEDA DAS FLORES LUBDIVISION, IN VIÇOSA/AL

SANTOS, Everson de Oliveira; SANTOS, Cirlene Jeane Santos e; MEDEIROS, Paulo Ricardo Petter; SOUZA, Letícia Rosendo Correia; OLIVEIRA JÚNIOR, Jarbas Macena de; LIMA, João Victor Alves de; SILVA, Ingrid Thainã Vieira da

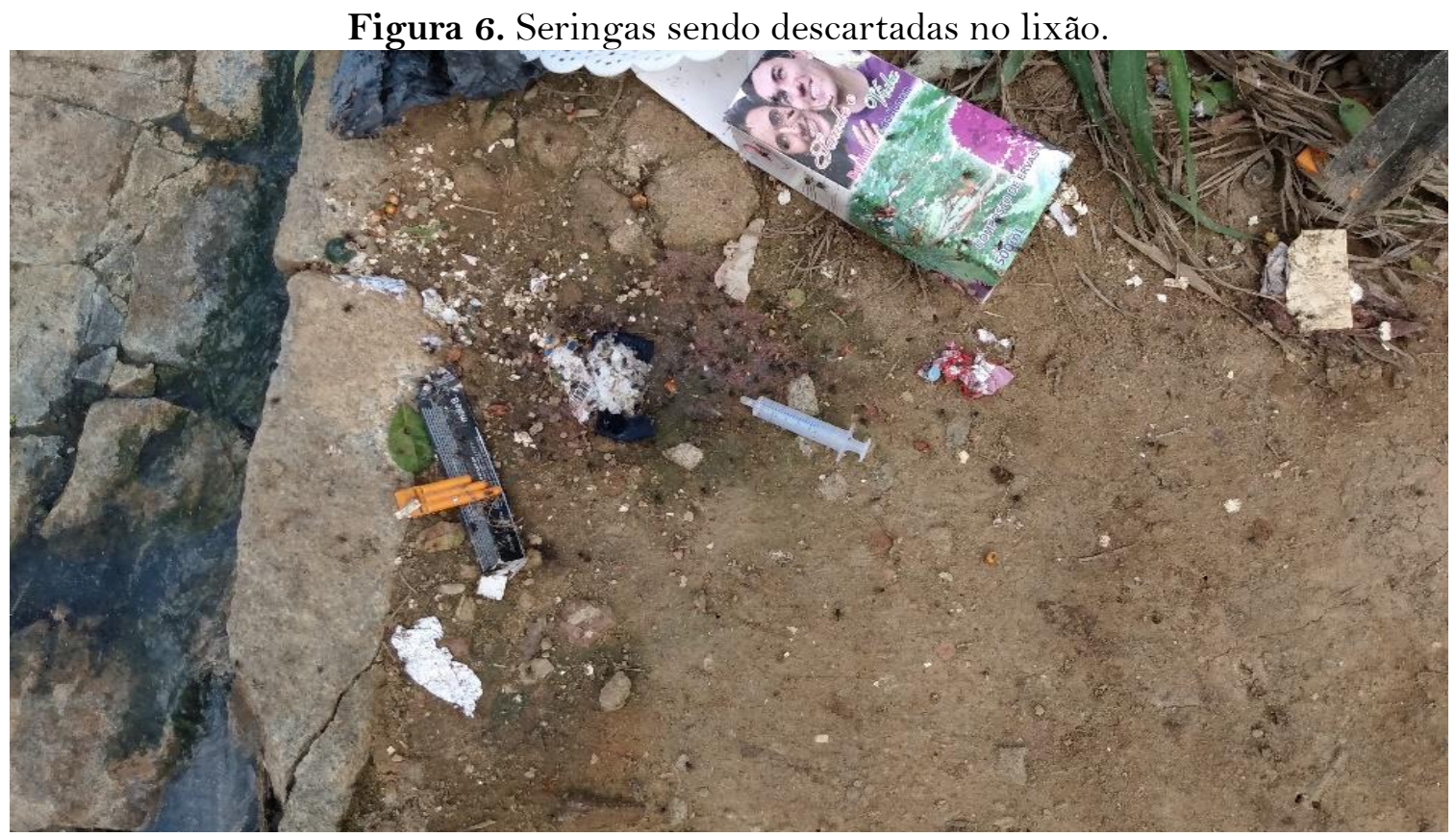

Fonte: Acervo dos autores, 2020.

Há uma quantidade significativa de fraudas ecológicas descartadas no lixão. Isso traz um prejuízo ao meio ambiente não apenas pelo odor, mas também pelo fato de conter material com dejetos humanos e coliformes fecais a céu aberto, ver figura 7 .

Figura 7. Fraudas ecológicas com fezes causando odor e possibilidade de contaminação.

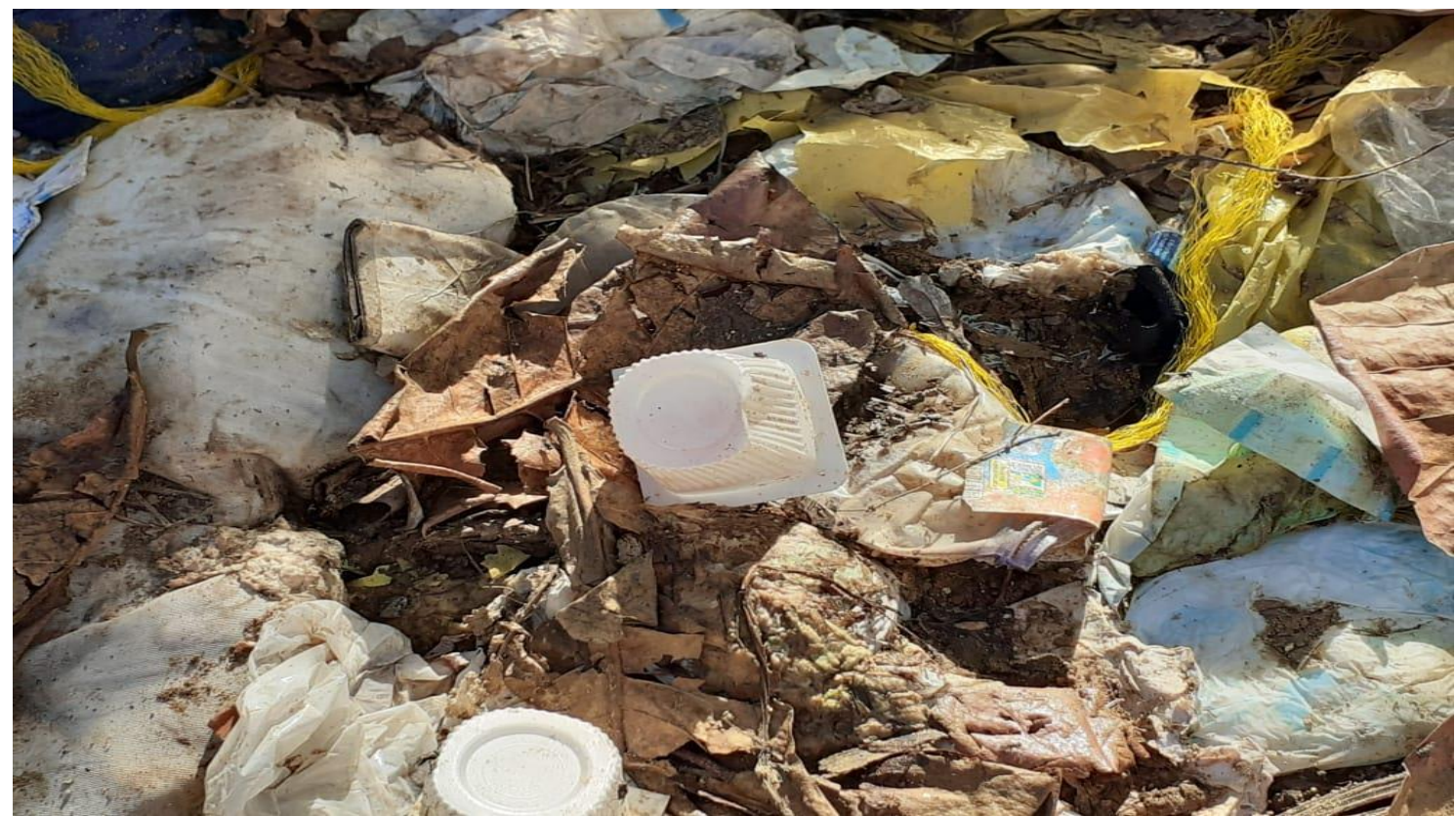

Fonte: Acervo dos autores, 2020. 
DIAGNÓSTICO DE IMPACTO AMBIENTAL REFERENTE AO DEPÓSITO DE RESÍDUOS SÓLIDOS URBANOS (RSUS) NO CONTATO ENTRE O BAIRRO CIDADE DE DEUS E O LOTEAMENTO ALAMEDA DAS FLORES, EM

DIAGNOSIS OF ENVIRONMENTAL IMPACT RELATED TO THE DEPOSIT OF SOLID URBAN WASTE (RSUS) IN THE CONTACT BETWEEN THE CIDADE DE DEUS NEIGHBORHOOD AND THE ALAMEDA DAS FLORES LUBDIVISION, IN VIÇOSA/AL

SANTOS, Everson de Oliveira; SANTOS, Cirlene Jeane Santos e; MEDEIROS, Paulo Ricardo Petter; SOUZA, Letícia Rosendo Correia; OLIVEIRA JÚNIOR, Jarbas Macena de; LIMA, João Victor Alves de; SILVA, Ingrid Thainã Vieira da

Animais mortos, segundo moradores, já foram colocados no lixão. Segundo eles, não se sabe por quem e provavelmente por pessoas que moram em áreas mais distantes do Loteamento. Além de provocar um constante odor desagradável e facilitar a proliferação de pragas, no processo de decomposição dos restos mortais pode ocorrer a contaminação do lençol freático, principalmente após uma precipitação pluviométrica.

Outro aspecto observado é a constante presença de moscas no lixão. O lixo amontoado, como por exemplo, o resto de comida, é um fator atrativo para esses insetos. O lixo orgânico acumulado é o suficiente para a mosca reproduzir e se espalhar pela vizinhança. Isso aumenta o risco de transmissão de doenças causadas por vírus e bactérias.

Para se ter uma noção, durante o processo de decomposição da matéria orgânica biodegradável do lixo (resto de alimentos) ocorre à liberação de gases poluentes que, por sua vez, provoca a poluição do ar, além do chorume, que a caba por poluir o lençol freático. Enfim, se não efetuada a limpeza de lixo urbano como um todo e de maneira eficiente as consequências são as mais diversas: poluição do ar, do solo, das águas, etc. Outro agravante é a proliferação de doenças como diarreia, amebíase, parasitose, entre outras.

\section{Contaminação do abastecimento de água domiciliar e solo}

A via de acesso principal ao Loteamento Alameda das Flores no qual é realizado o descarte do lixo não possui pavimentação. Como pode ser observado nas figuras 8 e 9 . 
DIAGNÓSTICO DE IMPACTO AMBIENTAL REFERENTE AO DEPÓSITO DE RESÍDUOS SÓLIDOS URBANOS (RSUS) NO CONTATO ENTRE O BAIRRO CIDADE DE DEUS E O LOTEAMENTO ALAMEDA DAS FLORES, EM

DIAGNOSIS OF ENVIRONMENTAL IMPACT RELATED TO THE DEPOSIT OF SOLID URBAN WASTE (RSUS) IN THE CONTACT BETWEEN THE CIDADE DE DEUS NEIGHBORHOOD AND THE ALAMEDA DAS FLORES LUBDIVISION, IN VIÇOSA/AL

SANTOS, Everson de Oliveira; SANTOS, Cirlene Jeane Santos e; MEDEIROS, Paulo Ricardo Petter; SOUZA, Letícia Rosendo Correia; OLIVEIRA JÚNIOR, Jarbas Macena de; LIMA, João Victor Alves de; SILVA, Ingrid Thainã Vieira da

Figura 8. Vista frontal da entrada principal ao Loteamento Alameda das Flores.

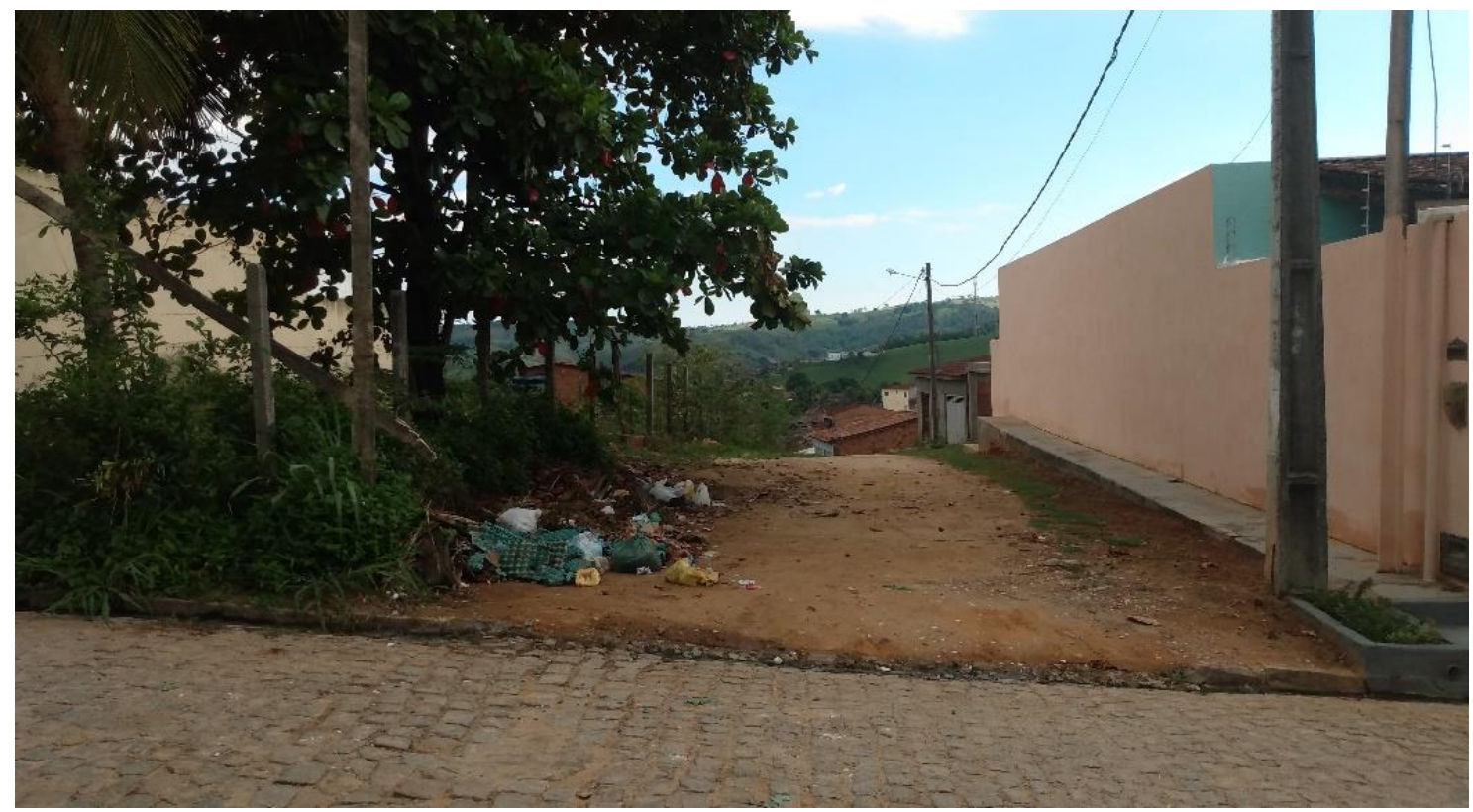

Fonte: Acervo dos autores, 2020.

Figura 9. Vista lateral e da bifurcação com via principal do Mutirão Cidade de Deus.

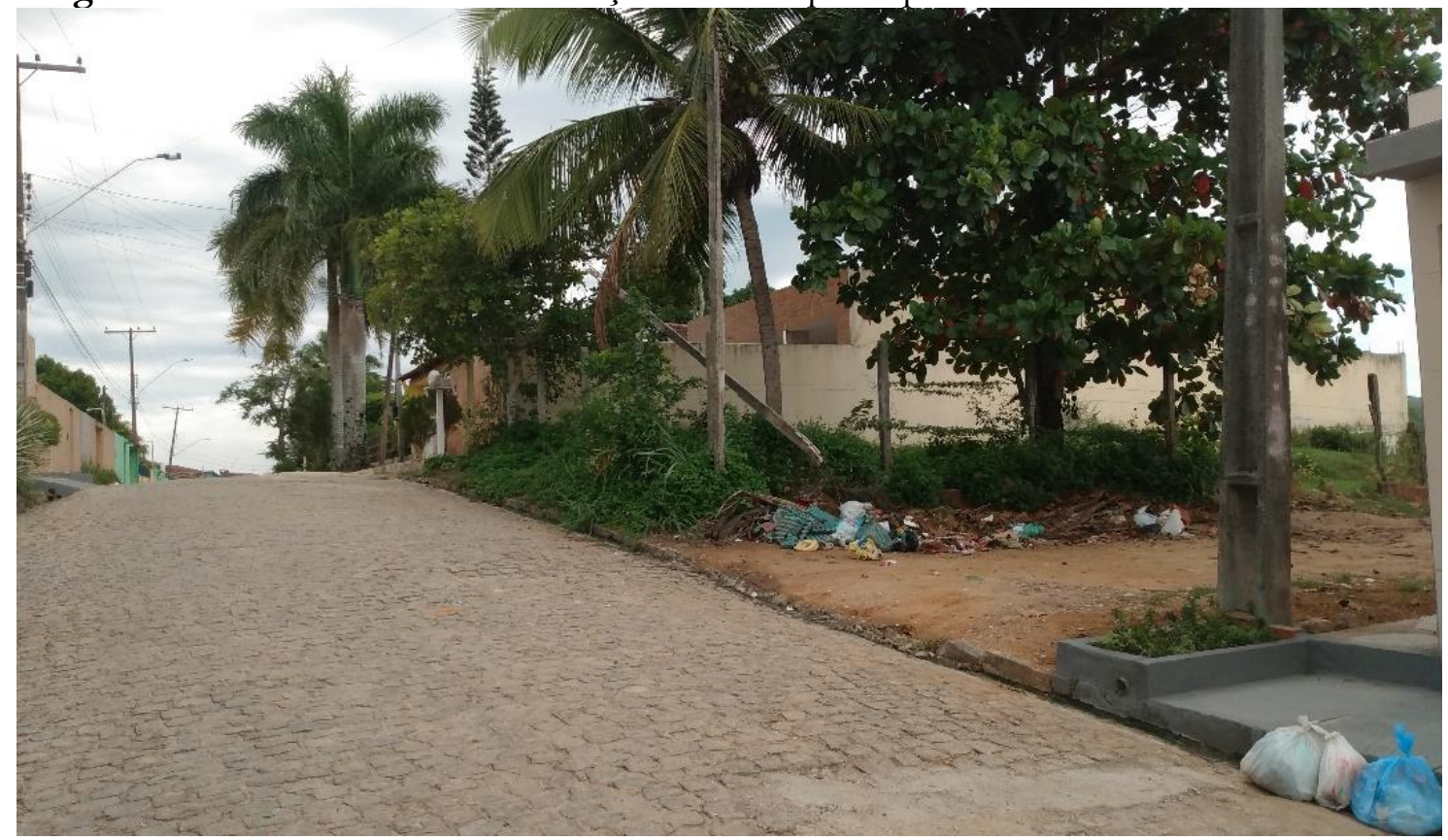

Fonte: Acervo dos autores, 2020.

Desse modo, em se tratando de uma via sem revestimento adequado o lixo fica sobre o solo que, por sua vez, está sujeito à contaminação do mesmo. Acrescentando a isso o fato de que após a ocorrência de chuvas ocorre a infiltração e percolação da água pluvial e consequentemente também do composto químico (chorume) gerado a partir da 
DIAGNÓSTICO DE IMPACTO AMBIENTAL REFERENTE AO DEPÓSITO DE RESÍDUOS SÓLIDOS URBANOS (RSUS) NO CONTATO ENTRE O BAIRRO CIDADE DE DEUS E O LOTEAMENTO ALAMEDA DAS FLORES, EM

DIAGNOSIS OF ENVIRONMENTAL IMPACT RELATED TO THE DEPOSIT OF SOLID URBAN WASTE (RSUS) IN THE CONTACT BETWEEN THE CIDADE DE DEUS NEIGHBORHOOD AND THE ALAMEDA DAS FLORES LUBDIVISION, IN VIÇOSA/AL

SANTOS, Everson de Oliveira; SANTOS, Cirlene Jeane Santos e; MEDEIROS, Paulo Ricardo Petter; SOUZA, Letícia Rosendo Correia; OLIVEIRA JÚNIOR, Jarbas Macena de; LIMA, João Victor Alves de; SILVA, Ingrid Thainã Vieira da

decomposição de muitos elementos (alimentos, animais mortos, etc) presentes no lixão e que acabam por contaminar também o lençol freático, esse circuito pode ser observado na figura 10 .

Figura 10. Ilustração da contaminação do lençol freático.

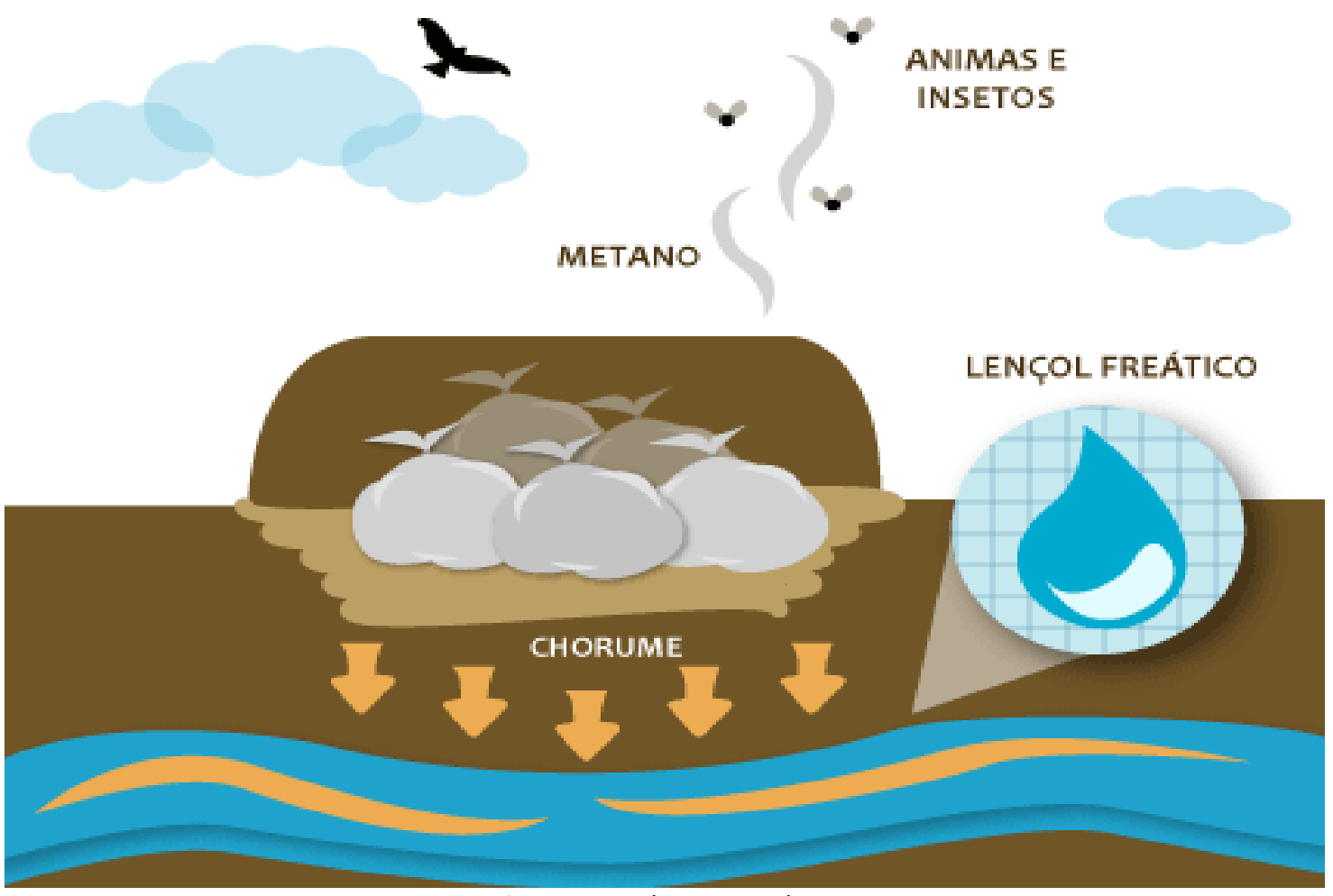

Fonte: Arte, Marina Martins, EcoD.

Foi verificado ainda, a presença de material de solo alóctone sobre o primeiro horizonte de solo originário da área. Tal material alóctone por não ter compactação natural influencia na maior facilidade de infiltração e percolação de fluidos em geral. Esse material alóctone (piçarro) é colocado como uma maneira de facilitar o acesso de moradores - algo muito comum em vias não pavimentadas.

Foi verificado em pesquisa de campo que justamente abaixo do lixão, soterrado por piçarro, passam encanamentos com água potável para abastecimento das primeiras residências do Loteamento - vide figura 11. 
DIAGNOSIS OF ENVIRONMENTAL IMPACT RELATED TO THE DEPOSIT OF SOLID URBAN WASTE (RSUS) IN THE CONTACT BETWEEN THE CIDADE DE DEUS NEIGHBORHOOD AND THE ALAMEDA DAS FLORES LUBDIVISION, IN VIÇOSA/AL

SANTOS, Everson de Oliveira; SANTOS, Cirlene Jeane Santos e; MEDEIROS, Paulo Ricardo Petter; SOUZA, Letícia Rosendo Correia; OLIVEIRA JÚNIOR, Jarbas Macena de; LIMA, João Victor Alves de; SILVA, Ingrid Thainã Vieira da

Figura 11. Em evidência encanamentos que garantem acesso a água potável às residências sem proteção adequada em via não pavimentada.

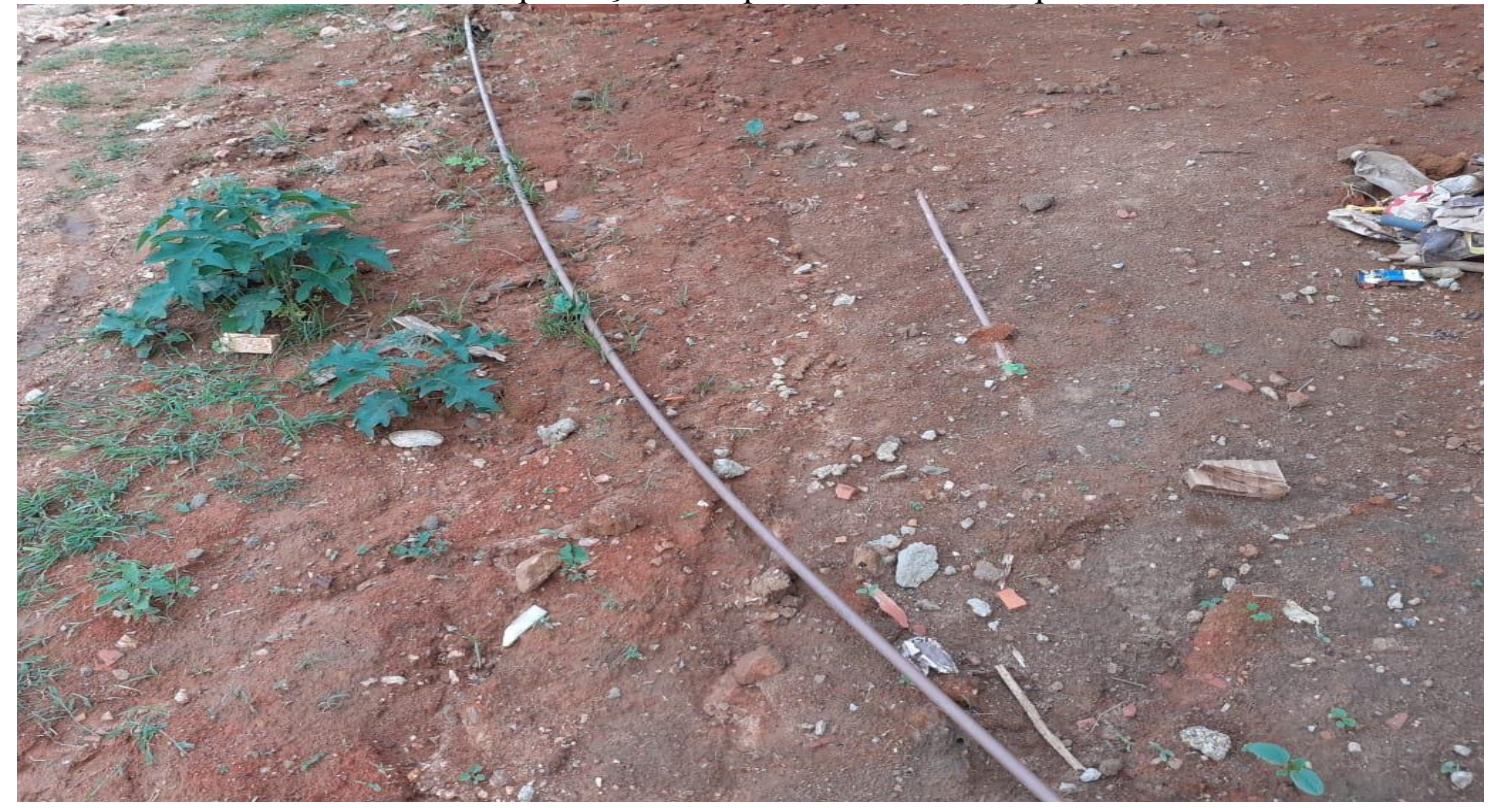

Fonte: Acervo dos autores, 2020.

Essa situação acaba por se configurar em um risco a saúde dos moradores, visto que, por exemplo, um cano estoura ou possuir vazamentos (como já aconteceu, segundo moradores), o solo contaminado por compostos químicos gerados pelo lixão acaba por se diluir na água que é levada as residências.

A figura 11 demonstra a fragilidade que os encanamentos estão sujeitos, considerando que não há pavimentação na via em questão. A referida imagem foi feita próxima ao lixão e por motivos de segurança e respeito aos moradores do local, os profissionais envolvidos na pesquisa não retiraram o piçarro base do lixão para fotografar os encanamentos que passam por baixo deste, para não correr o risco de danificar os mesmos

\section{Em relação à paisagem urbana e o impacto econômico}

A paisagem é uma categoria analítica da ciência geográfica e a mesma pode ser definida segundo Santos (1998, p. 61) como "tudo aquilo que nós vemos, o que nossa visão alcança, é a paisagem (...). Não apenas formada de volumes, mas também de cores, movimentos, odores, sons, etc.”. É neste sentido que a paisagem urbana tem uma 
DIAGNÓSTICO DE IMPACTO AMBIENTAL REFERENTE AO DEPÓSITO DE RESÍDUOS SÓLIDOS URBANOS (RSUS) NO CONTATO ENTRE O BAIRRO CIDADE DE DEUS E O LOTEAMENTO ALAMEDA DAS FLORES, EM

DIAGNOSIS OF ENVIRONMENTAL IMPACT RELATED TO THE DEPOSIT OF SOLID URBAN WASTE (RSUS) IN THE CONTACT BETWEEN THE CIDADE DE DEUS NEIGHBORHOOD AND THE ALAMEDA DAS FLORES LUBDIVISION, IN VIÇOSA/AL

SANTOS, Everson de Oliveira; SANTOS, Cirlene Jeane Santos e; MEDEIROS, Paulo Ricardo Petter; SOUZA, Letícia Rosendo Correia; OLIVEIRA JÚNIOR, Jarbas Macena de; LIMA, João Victor Alves de; SILVA, Ingrid Thainã Vieira da

importância fundamental em relação ao que moradores e visitantes podem perceber geograficamente. A ausência de uma ação coordenada e eficiente em relação à limpeza do lixo urbano como cumprimento de um dos pilares do saneamento básico e exigências legais do Plano Diretor e da PNRS acaba por provocar impactos na paisagem urbana o que, por sua vez, vai incidir diretamente em negativos impactos econômicos.

O Loteamento Alameda das Flores é um empreendimento que está sendo suscetível a desvalorização fundiária no processo de vendas e atratividade de interessadosem morar no mesmo. Vários fatores têm influenciando esse processo de depreciação e perpassa não apenas pela questão do lixão, mas da dificuldade de acesso ao Loteamento com vias pavimentadas.

É verificável também que não apenas residências do próprio Loteamento estão sofrendo esse impacto na paisagem urbana e malbaratoeconômico, devido, sobretudo, a existência do lixão. Moradias próximas que fazem parte do Mutirão Cidade de Deus (áreas 3 e 4) também se inserenesse rápido processo de desvalorização dos imóveis.

\section{CONSIDERAÇÕES FINAIS}

As considerações finais são desenvolvidas com a indicação de medidas mitigadoras. Levando em consideração toda situação descrita no diagnóstico, à equipe participante do referido estudo, somada a consulta aos moradores, as exigências legais e atribuições previstasna Política Nacional de Resíduos Sólidos e o Plano Diretor de Viçosa, sugere as seguintes indicações como medidas mitigadoras:

- Pavimentação da via principal de acesso ao Loteamento, inicialmente. Posteriormente deve haver pavimentação de todas as vias circundantes;

- Coleta seletiva dentro do Loteamento, na medida do possível - a pavimentação facilitará o acesso do transporte coletor;

- Retirada e limpeza imediata e total do lixão dando destino adequado ao conteúdo do mesmo;

- Colocar uma placa de proibição de descarte de lixo, autorizada pelo órgão competente; 
DIAGNÓSTICO DE IMPACTO AMBIENTAL REFERENTE AO DEPÓSITO DE RESÍDUOS SÓLIDOS URBANOS (RSUS) NO CONTATO ENTRE O BAIRRO CIDADE DE DEUS E O LOTEAMENTO ALAMEDA DAS FLORES, EM

VIÇOSA/AL

DIAGNOSIS OF ENVIRONMENTAL IMPACT RELATED TO THE DEPOSIT OF SOLID URBAN WASTE (RSUS) IN THE CONTACT BETWEEN THE CIDADE DE DEUS NEIGHBORHOOD AND THE ALAMEDA DAS FLORES LUBDIVISION, IN VIÇOSA/AL

SANTOS, Everson de Oliveira; SANTOS, Cirlene Jeane Santos e; MEDEIROS, Paulo Ricardo Petter; SOUZA, Letícia Rosendo Correia; OLIVEIRA JÚNIOR, Jarbas Macena de; LIMA, João Victor Alves de; SILVA, Ingrid Thainã Vieira da

- Ação coordenada e engenhosa entre a Secretaria de Infraestrutura e a equipe de Vigilância Sanitária no intuito de promover a educação ambiental de moradores do Loteamento Alameda das Flores e de moradores das proximidades (Mutirão Cidade de Deus, áreas 3 e 4);

- Parceria entre o setor privado(responsável pelo empreendimento) e setorpúblico no intuito de garantir que as moradias atualmente sujeitas a receber água com possível contaminação devido o chorume do lixão, conforme detalhado acima,tenham as suas encanações hidráulicas externas verificadas, visando garantir o recebimento da água de forma segura e sem risco de contaminação;

- Visitas periódicas de uma equipe formada pela Secretaria de Infraestrutura e Vigilância Sanitária do município para averiguar o andamento da situação após as ações sugeridas aqui.

Acreditamos que a partir dessas medidas mitigadoras a problemática em relação ao lixo que envolve o Loteamento Alameda das Flores e bairros adjacentes, seja equacionada. É importante destacar que a ação da Prefeitura é fundamental para o planejamento e ordenação urbana, essa constitui-se em um importante agente modelador do espaço, e a partir de suas intervenções ou na ausência delas, pode levar a valorização ou desvalorização fundiária na mesma velocidade.

\section{REFERÊNCIAS}

\section{ASSOCIAÇÃO BRASILEIRA DE NORMAS TÉCNICAS. NBR}

10.004/87: Resíduos Sólidos - Classificação. Ed. 2. 2004. 74 f.

2. $\quad$ BRASIL. Lei $\mathrm{n}^{\circ}$ 11.445, de Janeiro de 2007. Estabelece diretrizes nacionais para o saneamento básico. Diário Oficial da União: Seção 1, Brasília, DF.

3. BRASIL. Lei 12.305/10. POLÍTICA NACIONAL DE RESÍDUOS SÓLIDOS. Brasília, 2010.

\section{CONSTITUIÇÃO DA REPÚBLICA FEDERATIVA DO BRASIL.}

Brasília, DF: Senado Federal: Centro Gráfico, 1988, 292 p. 
DIAGNÓSTICO DE IMPACTO AMBIENTAL REFERENTE AO DEPÓSITO DE RESÍDUOS SÓLIDOS URBANOS (RSUS) NO CONTATO ENTRE O BAIRRO CIDADE DE DEUS E O LOTEAMENTO ALAMEDA DAS FLORES, EM

VIÇOSA/AL

DIAGNOSIS OF ENVIRONMENTAL IMPACT RELATED TO THE DEPOSIT OF SOLID URBAN WASTE (RSUS) IN THE CONTACT BETWEEN THE CIDADE DE DEUS NEIGHBORHOOD AND THE ALAMEDA DAS FLORES LUBDIVISION, IN VIÇOSA/AL

SANTOS, Everson de Oliveira; SANTOS, Cirlene Jeane Santos e; MEDEIROS, Paulo Ricardo Petter; SOUZA, Letícia Rosendo Correia; OLIVEIRA JÚNIOR, Jarbas Macena de; LIMA, João Victor Alves de; SILVA, Ingrid Thainã Vieira da

5. $\quad$ CUNHA, V.; CAIXETA FILHO, J. V. Gerenciamento da Coleta de

Resíduos Sólidos Urbanos: Estruturação e Aplicação de modelo não-linear de programação por metas. Revista Gestão e Produção. v.9, n.2, p.143-161, ago. 2002.

6. DIAS, C. R. Reciclagem do lixo urbano. Disponível em: $<$ ftp.unb.br/pub/UNB/admin/reciclagem/Reciclagem\%20do\%20Lixo\%20Urba no.doc >. Acesso em: 23 jul. 2008.

7. MONTEIRO, J. H. P. et al. Manual de Gerenciamento Integrado de resíduos sólidos. Coordenação técnica Victor Zular Zveibil. Rio de Janeiro: IBAM,2001. $200 \mathrm{p}$.

8. PENNA, A. M. Gerenciamento de Resíduos Sólidos e Líquidos. Instituto Prominas. Editora Prominas. 60 p.

9. PLANO DIRETOR PARTICIPATIVO DE VIÇOSA/AL. Lei n ${ }^{\circ}$ 740/2006, de 14 de dezembro de 2006. Viçosa, 2006.

10. SANTOS, Milton. Metamorfoses do espaço habitado. São Paulo: Hucitec, 1998.

11. UFV/LESA. Qual é o destino do lixo urbano e como diminuir seu impacto no ambiente. Disponível em: <http://www.ufv.br/lesa/images/leira>. Acesso em: 22 jul. 2008.

12. VIÇOSA (AL). Cartório de serviços Notoriais e Registrais de Viçosa Alagoas. Registro de Imóveis - livro 2 - Registro Geral. Registro em: 17 set. 2019.

13. ZANTA, V. M.; FERREIRA, C. F. A. Gerenciamento integrado de resíduos sólidos urbanos. Cap. 1. In: CASTILHOS JUNIOR, Armando Borges de (coord). Resíduos Sólidos - Gerenciamento de Resíduos Sólidos Urbanos comÊnfase na Proteção de Corpos D'Água: Prevenção, geração e tratamento de Lixiviados de aterros sanitários. Rio de Janeiro: ABES, 2006, 494p: il. (Projeto PROSAB: Programa de Pesquisa em Saneamento Básico 4). 